\title{
La llanura de Musashino en las afueras DE TOKIO: PAISAJES IMAGINADOS EN LOS LÍMITES DE LA CIUDAD
}

The Musashino plain on the outskirts of Tokyo: imagined landscapes in the city limits

\section{Iván Díaz Sancho \\ Doshisha Women's College of Liberal Arts nondaumal@yahoo.es}

\begin{abstract}
RESUMEN: La llanura de Musashino representa el entorno natural más representativo de Tokio, y el estudio minucioso de los cambios que sufre a lo largo del tiempo arroja datos de interés sobre el comportamiento urbanístico de la gran urbe en su expansión hacia zonas rurales; no sólo atendiendo a datos estadísticos — sociales o económicos—, sino también a la perspectiva cultural en la que se desarrolla la relación entre los conceptos de naturaleza y ciudad. El ensayo abarca un tiempo concreto que va desde los inicios del Japón imperial hasta el gran terremoto de Kantō en 1923.
\end{abstract}

Palabras clave: Llanura de Musashino, Tokio, expansión urbanística, Japón imperial, terremoto de Kantō.

RESUM: La plana de Musashino representa l'entorn natural més representatiu de Tòquio, i l'estudi minuciós dels canvis que pateix al llarg del temps llança dades d'interés sobre el comportament urbanístic de la gran urbs en la seua expansió cap a zones rurals; no sols atenent dades estadístiques - socials o econòmics-, sinó també a la perspectiva cultural en la qual es desenvolupa la relació entre els conceptes de naturalesa i ciutat. L'assaig recorre un temps concret que va des dels inicis del Japó imperial fins al gran terratrémol de Kantō en 1923.

Paraules clau: Plana de Musashino, Tòquio, expansió urbanística, el Japó imperial, terratrémol de Kantō. 
ABSTRACT: The plain of Musashino represents the most representative natural environment in Tokyo, and the thorough study of the changes that it undergoes over time yields data of interest on the urban behavior of the large city in its expansion into rural areas; not only attending to statistical data social or economic - but also to the cultural perspective in which the relationship between the concepts of nature and city develops. The essay covers a specific time that goes from the beginning of imperial Japan to the great Kantō earthquake in 1923.

KEYWORDs: Musashino plain, Tokyo, urban expansion, imperial Japan, Kantō earthquake.

\section{Contexto histórico y geográfico}

$\mathrm{E}$ n 1603, el shogún Tokugawa Ieyasu, ${ }^{1}$ tras vencer en la batalla de Sekigahara (1600) e imponerse a los soberanos feudales (daimyō) de las provincias del oeste, establece la ciudad de Edo, actual Tokio, como nueva capital del Japón unificado, inaugurando así el período Edo. Este período histórico, caracterizado en sus inicios por la persecución de los cristianos, la pacificación del país y el establecimiento de una política aislacionista respecto a las potencias extranjeras, se extenderá hasta 1868, año en el que se restituye el poder de facto del emperador y se da comienzo a la era Meiji, una etapa de occidentalización e industrialización que derivará en la militarización del Japón imperialista y el consabido desastre de la guerra del Pacífico.

1. En los nombres japoneses conservo el orden original con el apellido primero. 
Edo, originalmente un pueblo de pescadores, será el punto de partida para el desarrollo urbanístico de la bahía de Tokio. En 1590 Tokugawa Ieyasu se traslada desde Sunpu, en la actual Shizuoka, al castillo de Edo, iniciando una serie de grandes obras urbanísticas; entre ellas, el recubrimiento de la antigua ensenada de Hibiya con tierra del monte Kanda, el cual quedará considerablemente mermado. Así, bajo gobierno de Tokugawa, parte de la ciudad se construye sobre terreno ganado al mar para luego expandirse por la llanura de Kantō, la más extensa de Japón. Con una extensión de unos 17000 metros cuadrados, la llanura cubre las actuales provincias de Tokio, Saitama, Kanagawa, Chiba, Gunma y Tochigi y está constituida principalmente por mesetas como Ōmiya, Musashino, Sagamino y Joso, divididas a su vez en mesetas más pequeñas o terrazas. De todas ellas, la más conocida es Musashino, cuya fama se debe a la huella indeleble que desde tiempos antiguos han dejado sus paisajes en la imaginación de los japoneses a través del arte y la literatura, tal y como expondré en este artículo.

La meseta de Musashino, limitando al este con el río Sumida, se extiende desde el mismo corazón de Tokio hasta las montañas de Okuchichibu, una cordillera con picos de entre 1000 y 2600 metros de altura con la que limita al oeste. Al noreste, el río Ara; al sur, el río Tama (imagen 1). Esta delimitación geográfica de Musashino aparece descrita ya tempranamente en la Guía ilustrada de lugares célebres de Edo (Edo meisho zue, 1834), en una época en la que tuvo lugar un boom turístico y proliferaron las guías ilustradas. Con todo, cabe señalar que la guía no se limita a la descripción realista del lugar, sino que incluye además un listado de poemas clásicos que hacen referencia a la llanura, proyectando así una visión ficticia e idealizada sobre el paisaje. De hecho, debemos entender que durante el período Edo el interés de los visitantes no reside tanto en la observación objetiva del entorno como en la recreación de los paisajes y eventos narrados por la tradición literaria; algo que tendremos que tener en cuenta a la hora de explorar cómo ha sido percibida la llanura de Musashino a lo largo de la historia. 


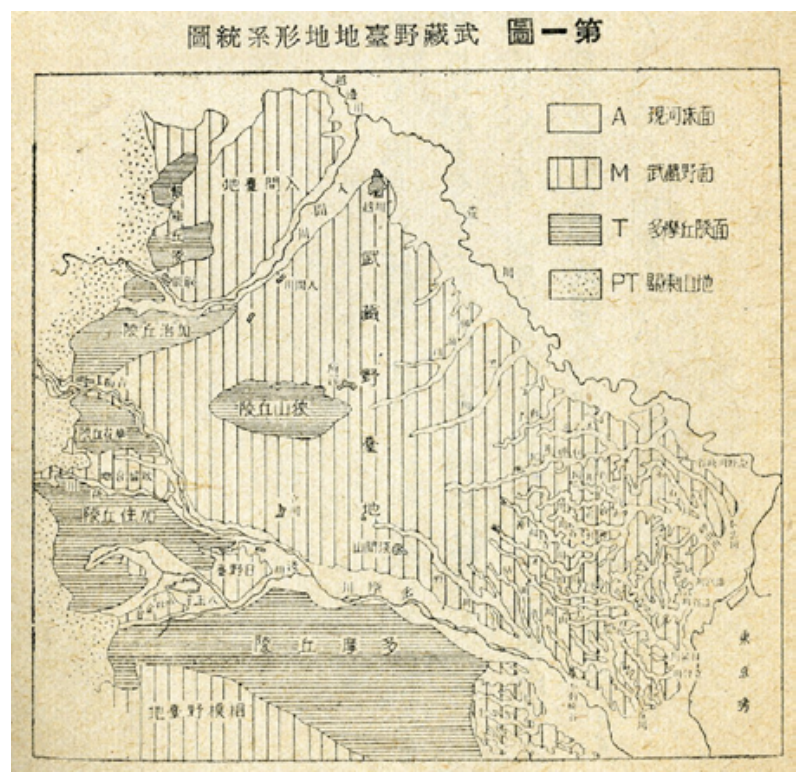

Imagen 1: Meseta de Musashino desde la bahía de Tokio (parte inferior-izquierda). Las rayas verticales se corresponden con la extensión de la llanura propiamente dicha. Fuente: Tsuyoshi, Honda, eds. (1941), Musashino.

Por su localización en las afueras de Tokio, la llanura de Musashino es un lugar privilegiado para estudiar la evolución del entorno natural en relación con el fenómeno de la urbanización de áreas rurales. Sin embargo, no es mi intención aquí establecer un análisis urbanístico de tipo social o económico y ni siquiera ecológico de las consecuencias sufridas en Musashino debido a la expansión de la ciudad. Mi interés principal reside en describir las transformaciones que sufre el paisaje en relación con el crecimiento de la urbe pero más bien desde el plano simbólico. Pensar la relación entre naturaleza y ciudad es pensar en cómo la naturaleza es percibida por parte de los habitantes de la ciudad, o bien de sus visitantes y de aquellos que la imaginan desde lugares lejanos; una percepción que no siempre se corresponde con la "imagen real", tal y como veremos, pero que no por ello es menos constituyente de realidad. Como seres humanos, parte de nuestra realidad está elaborada en base a procesos simbólicos y muchas veces lo que consideramos una "realidad objetiva" no es más que la proyección de un marco ideológico ligado a un contexto histórico particular. Así, nuestra interacción con la naturaleza no es solamente transformativa desde el punto de vista ecológico, sino 
que también repercute sobre nuestro plano psicológico y, en última instancia, sobre nuestra manera de estar en el mundo y de pensarlo.

\section{La imagen de Musashino a través de la historia}

Un acercamiento a los cambios sufridos en la percepción de la imagen del paisaje a lo largo de la historia nos puede ofrecer claves para comprender nuestra propia relación con la naturaleza, además de ser una herramienta ideal para explorar las transformaciones de nuestra visión del mundo en las distintas épocas; no solamente desde un plano puramente abstracto o filosófico, sino también en relación con fenómenos como el desplazamiento y concentración de la población; el encuentro o choque entre culturas diversas y los consecuentes procesos de aculturación; las luchas por el control del territorio y sus recursos naturales; la expansión de las grandes urbes; o el origen de las políticas para la protección del entorno; puntos, algunos de ellos, sobre los que planeará este artículo, pero que no trataré de forma directa. Finalmente, deberemos tener presente a lo largo de este artículo que la imagen de una naturaleza distante e idealizada fue siempre construida a partir de la visión de gente que habitaba en las ciudades (empezando por las antiguas capitales de Heijō-kyō o Heian-kyō en el caso de Japón). Esta idealización permite a los habitantes de la ciudad establecer los límites de lo que no es urbano para así construir, por contraste, su propia identidad de urbanitas (Flores Urushima, 2015).

En el caso que aquí nos ocupa, la llanura de Musashino se impone como el entorno natural más representativo de Tokio, por lo que un estudio atento sobre los cambios que ha sufrido a lo largo del tiempo puede aportarnos datos sobre el comportamiento urbanístico de la gran ciudad en su expansión hacia zonas rurales; un proceso que no puede explicarse meramente a través de datos estadísticos — sociales o económicos-, sin tener en cuenta la perspectiva cultural en la que se desarrolla la relación entre los conceptos de naturaleza y ciudad (para un estudio estadístico sobre la expansión de la ciudad ver Siebert, 2016). Kunikida Doppo, escritor activo desde finales del siglo XIX, remarcaba ya en 1901 la importancia de esta simbiosis entre Musashino y Tokio: 
En mi planteamiento, Tokio está en el centro de Musashino. [...] Para conocer el verdadero aspecto de Musashino, no basta solo con la idea de contemplar desde la llanura al monte Fuji, o desde Kōnodai en la cordillera de Chichibu, sino que hay que reflexionar partiendo de Tokio, que está en el centro de todo. (Kunikida 2016, versión digital)

Parafraseando a Kunikida, considero que tal planteamiento puede funcionar igualmente en el sentido inverso: para conocer el verdadero aspecto de Tokio hay que reflexionar partiendo de Musashino. Es por ello que me centraré aquí en la imagen de la llanura desde una perspectiva histórico-cultural. Por ejemplo, no pueden entenderse las primeras medidas de protección de zonas verdes en Tokio durante las primeras décadas del siglo XX (parques como Inokashira o Tama Reien) sin comprender antes el cambio en la visión de la naturaleza de Musashino a finales del s. XIX bajo la influencia del naturalismo literario, movimiento introducido en Japón desde Europa. Por otro lado, no puede captarse en su totalidad el impulso existente en los últimos años en la zona de Musashino por retornar al mundo rural - en concreto a la cultura rural del tardo período de Edo (ver, por ejemplo, el documental Musashino: Edo Circular Agriculture Lives, 2017) — sin comprender el significado simbólico que ha adquirido la llanura en la tradición artístico-literaria. Finalmente, tampoco se puede entender esta tendencia a retornar a un pasado histórico idealizado si no se tiene en cuenta la influencia de ideas ecologistas y nativistas difundidas por fenómenos populares como las películas de animación de Miyazaki Hayao y del estudio Ghibli, especialmente La princesa Mononoke (1997), fuertemente influida por la denominada "Evergreen forest culture theory", y Mi vecino Totoro (1988) y Pompoko (1994), ambas ambientadas en el entorno natural de Musashino. Significativo es también que el museo Ghibli esté precisamente ubicado en el barrio toquiota de Mitaka, localidad situada en pleno centro de la antigua llanura.

Con todo, por cuestiones de espacio, en este ensayo me limitaré a explorar a grandes rasgos la imagen de Musashino desde época pre-moderna hasta la modernización del país a finales del s. XIX y principios del s. Xx; desde las primeras descripciones en el período Nara y en los inicios del Japón imperial 
hasta el gran terremoto de Kantō de $1923 .^{2}$ Reservo para futuros estudios la era contemporánea, en la que se hace mucho más patente la interdependencia entre la naturaleza de Musashino y la ciudad de Tokio a través del folclore, la novela, el cine, la fotografía, el arte y los movimientos sociales.

\subsection{Imagen de Musashino entre los periodos de Nara y Edo}

Musashino fue originalmente un bosque laurifolio que terminó transformándose en una llanura a consecuencia de las prácticas de tala y quema ejercidas por el ser humano. Debido a que era una zona con escasez de agua, sus terrenos no eran aptos para el cultivo de arroz, por lo que hasta el período Heian (794-1185) no hubo grandes asentamientos de población, si bien se han hallado restos arqueológicos y cerámica del período Jōmon (c. 14000-300 a. C.). Esta peculiaridad en la hidrografía del terreno (ver Sumida 2015 y Sakurai 2010) contribuyó a que se preservara como planicie salvaje durante siglos, constituyéndose así un paisaje, el de la llanura, que calaría en el imaginario japonés hasta finales del S. XIX, aun a pesar de las grandes transformaciones sufridas durante el período Edo como resultado de la explotación agrícola (Yamane, M. et al., 1990).

La primera mención de Musashino (武蔵野) en la literatura la encontramos durante el período Nara (710-784) en el Manyōshū, una compilación de aproximadamente 4500 poemas denominados waka escritos entre el 600 y el 759 por gran variedad de autores. En el volumen 14, titulado Canciones del Este, se presentan algunos poemas referentes a la región de Musashino, conocida por aquel entonces como “el país de Musashi” (Musashi no kuni 武蔵の国). El origen del término Musashi no está claro, pero se ha especulado que puede provenir del lenguaje de los Ainu —etnia autóctona del norte de Japón que sufrió la aculturación y la marginación durante la época moderna-, o bien

2. En el texto se distingue entre los términos "período" y "era", haciendo corresponder el primero con el nombre de la capital que dominó un período histórico determinado (Heian, Nara, Kamakura, Edo), mientras que la era expresa una partición temporal basada en el tiempo que gobierna un emperador concreto. Los nombres de las eras (Meiji, Taishō, etc.) son términos extraídos de la literatura clásica, por lo que no se corresponden con el nombre de los emperadores que las gobiernan, si bien estos reciben el nombre de la era como epíteto (Emperador Meiji, Emperador Heisei, Emperador Reiwa, etc). 
del idioma coreano, siendo de cuño posterior el sufijo -no (野), que equivale en japonés a prado o llanura. No debemos perder de vista que optar por una $u$ otra tesis implica a su vez posicionarse ideológicamente sobre el origen de la cultura japonesa (Unno 1999; Iketani 2005), lo que demuestra que Musashino es también un buen punto de partida para estudiar cómo la formación del paisaje va ligada a la conformación del concepto de patria o nación, un tema muy atractivo, pero en el que no entraré en este ensayo, de carácter más descriptivo. Propiamente hablando deberíamos traducir Musashino como la "llanura de Musashi", pero el sufijo -no, con significado de llanura, se ha convertido ya en parte del nombre, por lo que es común hablar de "llanura de Musashino" en nuestra lengua. Lo mismo sucede en ocasiones con sufijos japoneses como -ji (templo) o -kawa y -gawa (río), cuyo uso en inglés o español es a veces arbitrario. Por ejemplo, es común hallar referencias tanto al "río Tamagawa" como al "río Tama".

En los poemas del Manyōshū aparecen expresiones generalmente asociadas a las plantas silvestres de la llanura, lo que contribuye a fijar la imagen de Musashino como una "llanura de hierbas silvestres" (yasō no no). El poema número 3376, de autor desconocido, es representativo de ello: «Por tu amor ondearé mi manga, pero evitemos mostrar los colores como en la llanura de Musashi la flor de ukera» (Traducción hecha por el autor. La traducción sigue lo más fielmente posible el sentido original, en detrimento de la partición rítmica y los recursos retóricos).

Un ligero movimiento de las mangas anchas del kimono en forma de saludo es suficiente para confirmar el amor mutuo que sienten los amantes; pero el disimulo es indispensable para no revelar su secreto frente al resto de los presentes, algo que significaría el fin de su relación, según solía creerse en la época. Ukera (atractylodes japonica) es una planta silvestre similar al cardo, de antiguo uso medicinal y comestible, cuya flor, generalmente blanca o rosada, aun sin ser muy vistosa destaca cuando florece, igual que un rostro cuando se sonroja. El gesto de la manga confirma un amor secreto que corre el peligro de descubrirse si los amantes se sonrojan.

Esa misma imagen de Musashino como llanura silvestre reaparece en textos del período Heian (794-1185). Uno de los episodios más conocidos lo encontramos en la sección 12 de Cuentos de Ise (Ise Monogatari, fecha 
y autor desconocidos). En él se relata la historia de un bandolero que rapta a la hija de un cortesano. Cuando, perseguidos por los agentes de la ley, se adentran en Musashino, el ladrón huye, dejando sola a la doncella escondida entre los matojos de hierba (kusamura). Los perseguidores, pensando que el ladrón sigue en la llanura, se disponen a prenderle fuego. Entonces la doncella recita un poema para persuadirlos: «No prendáis fuego aún a Musashino, que mi amado está aquí escondido y yo con él». Este episodio será el tema de gran cantidad de pinturas durante períodos posteriores. Destaca, entre ellas, la obra conocida como "Ise Monogatari: Musashino (papel coloreado)" de Tawaraya Sōtatsu (c. 1570 - c. 1640), uno de los pioneros de un estilo posteriormente conocido como Rinpa y caracterizado por el uso del pan de oro. En el centro de la imagen vemos a una pareja con ropajes cortesanos que yacen tumbados entre las hierbas de la llanura, mientras que en primer plano, en la parte inferior, un grupo de hombres entran en escena portando antorchas encendidas (imagen 2).

Imagen 2: Tawaraya Sōtatsu. Ise Monogatari Musashino [Shikishi].

Ver online: https://asia.si.edu/exhibition/musashino-tales-of-ise-episode-12/

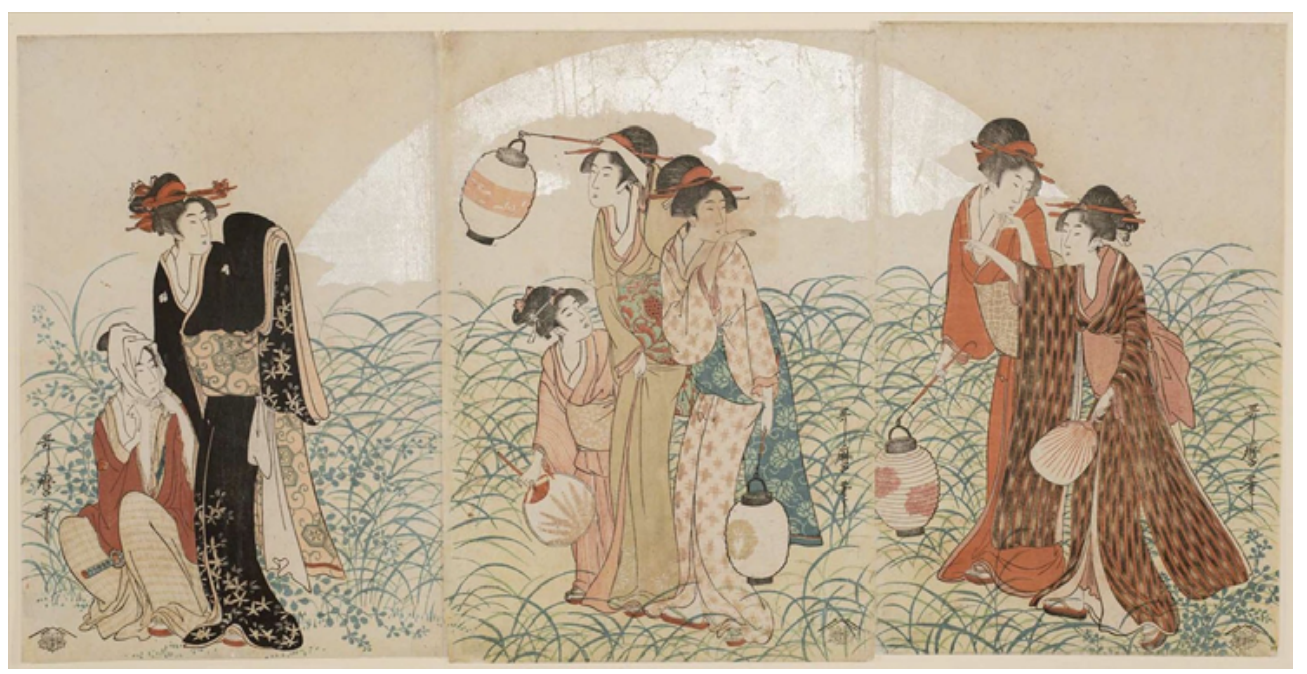

Imagen 3: Kitagawa Utamaro. Mitate Ise Monogatari [Grabado]. (Fuente: Public Domain Museum of Art, http://www.bestweb-link.net/PD-Museum-of-Art/ ukiyoe/html/1440_utamaro-5.html) 
A la izquierda descubrimos a la pareja semiescondidos entre las hierbas: el hombre de cuclillas y la mujer de pie junto a él, alzando en alto la manga ancha de su kimono negro para disimular la presencia de ambos. Los perseguidores con antorchas de la historia original se han transformado aquí en jovencitas que caminan en la oscuridad con farolillos. Parecen buscar al hombre, quien podría ser un actor de kabuki de moda o simplemente un seductor con éxito entre las “cortesanas". Por la empuñadura de katana que asoma entre sus piernas, reminiscencia fálica, intuimos que es un samurái. El gesto con la manga de su compañera parece intentar bloquear la vista de sus rivales en mitad de la noche. Al fondo de la escena, una enorme luna plateada asoma entre las hierbas. Si bien la escena hace referencia al episodio de Cuentos de Ise, la ropa de los personajes que aparecen en el grabado es típica del tardo período Edo (c. 1750-1850). Este tipo de anacronismo es común en la época y está basado en el mitate, un recurso estético consistente en superponer figuras y lugares de distintos contextos culturales por medio de la alusión y cuya intención suele ser satírica, al identificar lo sublime con lo inferior; en este caso, a los cortesanos de la historia original con cortesanas (en el sentido de prostitutas).

Desde la era Heian, este paraje ignoto, teñido de romanticismo, estimulará la imaginación de los habitantes de la capital imperial (Heian-kyō, actual Kioto), quienes terminarán creyendo que toda la región de Musashino es una llanura poblada íntegramente por plantas y flores que crecen a su antojo hasta el infinito, a pesar de que en realidad la geografía de la meseta constaba de numerosos desniveles, colinas y terrazas, además de algunas zonas boscosas. El paisaje de la llanura se establece así como estereotipo de la belleza natural y salvaje, desatando la imaginación de los poetas hasta el punto de que vemos que todavía en el período Heian la "llanura de hierbas silvestres" pasa a ser "llanura de violetas" (murasaki no no) en textos como el Kokinshū (Colección de poemas antiguos y modernos, 905). Sin embargo, esta imagen no se corresponde con la realidad, tal y como constatará un siglo más tarde en su Diario de Sarashina (Sarashina nikki, c. 1058) la hija de Sugawara no Takasue, de quien se desconoce el nombre: «En la llanura donde se dice que crecen las violetas no crecen más que altos juncos y carrizos y no se aprecia particularmente ningún lugar fuera de lo común». Posteriormente el renombrado poeta Matsuo Bashō escribirá su propio Diario de viaje de Sarashina 
(Sarashina kikō, 1688-89), en el que explora algunos de los lugares célebres cantados por la tradición literaria.

En el período Kamakura (1185-1333), con la popularización de los diarios de viaje $(k i k \bar{o})$ se continúa idealizando la llanura, pero esta pasa a recibir el epíteto de "llanura vasta e interminable" (bōbaku no no). De esta época es la imagen de un paisaje desolador en el que se proyectan las penas e inseguridades de los viajeros, atmósfera a la que contribuye el tópico literario de la luna en otoño: «En la llanura de Mushashi, no habiendo picos donde ponerse la luna, nubes blancas se posan sobre los pastos de obana». La obana, también denominada susuki (myscanthus sinensis) florece en otoño formando en su extremo una especie de pelusa blanca, en ocasiones púrpura, cuyo color queda acentuado por los rayos de la luna. El poema juega con la analogía de las nubes y las flores; un efecto visual solo posible gracias a la ausencia de montañas en la llanura, lo que sugiere una continuidad visual sin cisuras entre cielo y tierra. Se establece así la imagen de Musashino como una pampa extensa repleta de ogi, ashi, obana o susuki (plantas herbáceas autóctonas similares a carrizos y eulalias), al tiempo que se convierte en un "lugar célebre para contemplar la luna" (tsuki no meisho). La imagen combinada de luna y plantas silvestres tendrá gran éxito, reapareciendo con frecuencia en épocas posteriores, tal y como hemos visto en el grabado de Utamaro.

Una de las obras más curiosas al respecto son los "Biombos con la imagen de Musashino" (Musashino-zu byōbu), una pareja de biombos de seis paneles cada uno, de autor anónimo y datados en la primera mitad del período Edo, actualmente conservados en el museo Fuji de Tokio. Estos biombos estaban pensados para situarse uno frente al otro, a izquierda y derecha de quienes se sentaban a contemplarlos. Existen variedad de biombos con el mismo motivo y el mismo nombre, Musashino-zu byōbu, siendo destacables el del museo Suntory, que carece de montañas, y el conservado en el museo Edo de Tokio, que reúne los motivos del monte Fuji y de la luna entre las hierbas en un mismo biombo de seis paneles. "El biombo de la derecha" (右隻, useki) en el museo Fuji presenta un paisaje imposible (imagen 4).

Imagen 4: Anónimo. Musashino-zu-byōbu [Pintura sobre Biombo]. Tokio, Museo Tokyo Fuji. Ver la imagen en Google Arts: https://artsandculture.google.com/ asset/KAF0fcyexBGQXQ?h1 
En la mitad inferior apreciamos hierbas y flores otoñales con los tallos de susuki elevándose hacia lo alto. En la mitad superior, las flores pomposas y plateadas de susuki han sido sustituidas poéticamente por nubes de pan de oro que atraviesan de lado a lado el biombo, dividiéndolo horizontalmente en dos partes. El hecho de que flores y nubes se superpongan contribuye a la sensación de que tierra y cielo forman un continuo (las nubes pueden interpretarse también como mera neblina). En el mismo museo se conserva otra pareja de biombos anónimos con el mismo tema en el que se representan algunas cabañas escondidas entre las hierbas silvestres y nubes o niebla de pan de oro flotando entre ellas. Las plantas superan la altura de los tejados, mientras que en un rincón asoma la figura plateada de una luna menguante. En el caso del "biombo de la derecha" "biombo de la derecha" en cuestión, sobre las nubes doradas apreciamos las montañas en la lejanía (el motivo de las nubes tiene también en la tradición japonesa una función puramente técnica para crear perspectiva o sensación de profundidad). Hasta aquí nada extraño, puesto que las nubes o neblina rodeando una montaña conforman un fenómeno apreciable en la naturaleza, pero entonces descubrimos una presencia circular escondida entre las hierbas. Se trata en realidad de la luna llena, aunque no está situada en el cielo, sino a ras del suelo, como si se tratara de una pelota perdida entre la vegetación. Este motivo tan peculiar (la luna entre las hierbas) está inspirado en una variación popular del poema del Kokinshū citado algunas líneas más arriba: «En la llanura de Mushashi, no habiendo picos donde ponerse la luna, de las hierbas sale y en las hierbas se pone».

La representación de Musashino en este biombo es significativa de que el "aspecto real" de la llanura ha pasado a un segundo plano; se trata más bien de un juego de referencias, con el añadido de un sentido del humor muy peculiar de la estética de Edo. La luna entrevista entre las hierbas contribuye además a crear una atmósfera irreal y fantástica que será retomada a principios del siglo xx por el escritor Izumi Kyōka en Laberinto de hierba (Kusa meikyū, 1908). Esta novela narra la historia de un joven que viaja por todo el país tratando de escuchar de nuevo la "canción para juego de pelota" (temariuta) que le cantaba su madre en la niñez y cuya letra ha olvidado. Al inicio de la novela, el autor utiliza como modelo la imagen del biombo en cuestión para describir el aspecto de un acantilado junto al mar: «Desviando ligeramente la 
mirada, el cambio en el paisaje era rotundo, como pasar de los lirios morados de Yatsuhashi [título de otro biombo de estilo Rinpa] a la luna de la pradera de Musashino» (Kyōka 2014: 29). En apariencia no es más que una referencia breve, pero a medida que avanzamos en la novela nos damos cuenta de que la imagen del biombo se superpone a la historia, teniendo la hierba de Musashino su paralelo en la hierba del título de la novela y la luna en la pelota de hilo tradicional (temari) de la que se habla en la narración.

Un detalle como este, aparentemente desligado del tema de la naturaleza y la urbe, es muy significativo para un estudio del imaginario de Musashino si tenemos en cuenta que Izumi Kyōka, aun siendo un autor moderno en pleno desarrollo urbanístico de Tokio, se resiste a la modernización en su estilo y en sus temas; esto es, se percibe en su obra no solo cierto rechazo de la literatura europea, sino también una tendencia a rememorar con nostalgia un Edo idealizado, un pasado idílico, ya perdido — si acaso llegó a existir nuncacuya imagen representativa es Musashino; la Arcadia hacia la que vuelve los ojos el Japón moderno y contemporáneo, a pesar de que en el período Edo la llanura era ya un paisaje alterado por la mano del hombre.

\subsection{Imagen de Musashino desde el período Edo hasta la era Meiji}

Durante el período Edo, en paralelo a la expansión de la capital, el paisaje de Musashino se transforma de forma considerable. En 1654 se canalizan las aguas del río Tama y en 1722 se emite una orden para introducir terrenos de cultivo como medida para estimular el desarrollo de la región. En las zonas bajas de la llanura, con el objetivo de aprovechar mejor los recursos de regadío, se roturan campos de arroz, mientras que en lo alto de las terrazas, donde el agua escasea, se propagan los huertos. A consecuencia de este desarrollo se generan también pequeños núcleos de población en torno a los cuales se plantan distintas especies de árboles que no eran autóctonas de la zona, principalmente coníferas como pinos y sugi (cedro japonés). La llanura va así poco a poco transformándose en un paisaje boscoso allá donde no sirve el terreno para el cultivo: bosquecillos en los recintos de santuarios y templos, árboles en los jardines de las mansiones de señores feudales (daimyō), arbo- 
ledas junto a los caminos para protegerlos de las ventiscas, etc. (Miyamoto 1981: 28).

Este será el origen de una imagen de Musashino que se idealizará más tarde en el s. xx e incluso en el s. XxI: por un lado bosques, el Musashino salvaje; por otro lado campos de cultivo, el Musashino rural. En este punto, deberíamos cuestionarnos qué entendemos por naturaleza, sobre todo cuando nos referimos a espacios naturales que limitan con zonas urbanizadas, puesto que, en ocasiones, aquello que hoy consideramos natural no fue antaño más que el resultado de una intervención artificial del ser humano.

La conversión de Musashino en un paisaje rural está ya documentada en el período Edo, por ejemplo en la guía de viaje ilustrada que lleva por título Historias de Musashino (Musashinobanashi, 1815). Observemos el caso de Hakonegasaki, un pueblo situado en el extremo oeste de la meseta, cerca de las montañas, en la actual localidad de Mizuho (imagen 5).

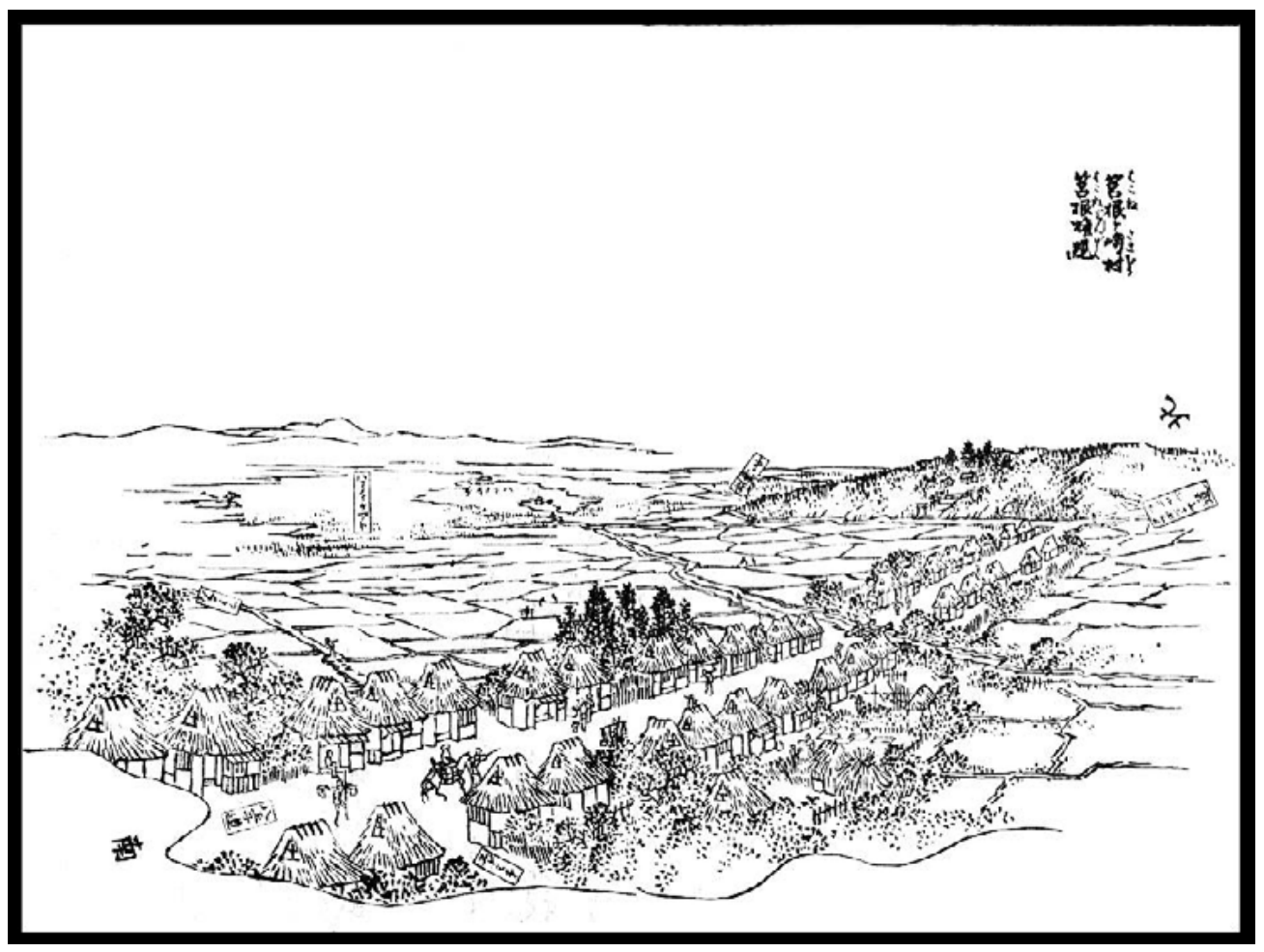

Imagen 5: Pueblo de Hakonegasaki. (Fuente: Saitō (1815), Musashinobanashi) 
En primer plano vemos un camino que cruza en diagonal de izquierda a derecha (de sur a norte, como aparece indicado en ideogramas) en dirección a una colina. Las casas se extienden a lo largo del camino, a ambos lados, en un tipo de asentamiento aglomerado muy típico de la zona conocido en japonés como roson, término geográfico acuñado de la palabra alemana Wegedorf (Watanuki 1935). El camino (y por ende el pueblo) divide en dos la llanura, la cual podemos ver que estaba por entonces conformada principalmente por campos de cultivo. En ese paisaje no parece quedar ni rastro de aquella planicie de hierbas silvestres de la que hablaban los antiguos poetas desde la antigua capital. Aun así, los ciudadanos de Edo no pudieron en realidad desprenderse completamente de la imagen ideal que se cantaba antaño en los poemas clásicos (waka); en parte por tratarse de una tradición que, desde su posición de capitalinos, se ven obligados a mantener y a continuar como cultura de prestigio. Aunque Edo estuviera habitado principalmente por comerciantes, estos necesitaban estar versados en la poesía clásica para elevar su estatus al nivel de los aristócratas de épocas imperiales; la educación, bajo influencia del confucianismo, se convierte además en una herramienta para eliminar barreras sociales.

Esa continuidad en la tradición cultural, a pesar del cambio de régimen del imperio al shogunato-, se refleja igualmente en la representación artística de Musashino, por lo que no es de extrañar que pertenezcan justamente a este período la mayoría de pinturas que hacen referencia a la llanura, como en el caso de algunas ya citadas. Tal proliferación de obras que toman como motivo las hierbas de susuki y la luna puede entenderse también por el hecho de que la pérdida progresiva del paisaje original genera un sentimiento de nostalgia que a su vez impulsa la creación artística. De este modo, en la imaginación de los habitantes de Edo, Musashino continuará siendo tanto la "llanura vasta e interminable" como un "lugar célebre para contemplar la luna", tal y como expresan algunas guías de la época: «Si ascendemos al monte Sayama en una noche de luna y dirigimos la mirada a los alrededores, podremos apreciar el aspecto [de la llanura] en épocas pasadas» (Saitō 1834: 270) o «[Fujimi-zaka] posee la mejor panorámica para contemplar la luna de Musashino y sentir la nostalgia de tiempos antiguos, junto a un vergel de árboles y plantas y con los campos de cultivo extendiéndose al infinito» (Saitō 1838: 168). Los campos de arroz y los huertos, por su parte, no desplazan esa imagen idílica 
de la llanura, sino que más bien contribuyen a su idealización, estimulando la curiosidad de los ciudadanos de la metrópolis. A medida que se expande la ciudad de Edo y crece su economía - dando pie a la aparición de nuevas formas de ocio-, Musashino se transforma en un lugar de ensoñación; un lugar distante pero a la vez cercano, a tiro de piedra para un día de excursión; un lugar exótico para el esparcimiento de los urbanitas, quienes canalizan en el nuevo paisaje de campos cultivados la nostalgia de un pasado bucólico que en realidad nunca experimentaron.

Se trata, al fin y al cabo, de un primer acercamiento al entorno natural como elemento integrado en la ciudad. A medida que la ciudad se expande hacia el campo, el ciudadano toma conciencia de la naturaleza como algo distinto, separado de la urbe, que despierta su curiosidad: el paisaje como pasatiempo, con frecuencia ligado a algún hito célebre del pasado. Se desata así una fiebre "turística" por descubrir los lugares imaginados en la tradición, sobre todo la vegetación frondosa bañada por la luz de la luna. Este boom, como ya sucedía en el grabado de Utamaro, no escapa a la mirada irónica de algunos artistas. En 1805, el poeta y monje Kobayashi Issa compone el siguiente haiku: «Oh, Musashino, también sobre las heces del perro el brillo de la luna». La obsesión por observar la luna desde la llanura se parodia aquí a pequeña escala, en el detalle de las heces del perro, las cuales conforman un monte Fuji en miniatura.

En esta misma época, además de la luna, suele asociarse frecuentemente Musashino con ese otro elemento natural, el monte Fuji: «Musashino, con su llanura de cientos de millas, la luz de la luna proyectándose sobre el río Tama e iluminando la cima del Fuji, presenta unas vistas insuperables». Este texto aparece escrito directamente sobre el mapa-guía Tōto kinkō-zu, Mapa de las afueras de la capital del Este publicado en 1825 (Yamane 1990; puede verse una copia de 1831 digitalizada por la National Diet Library: http:// dl.ndl.go.jp/info:ndljp/pid/2542726). Los cerros esparcidos por la llanura no son únicamente un lugar ideal para observar la luz del astro nocturno desde una posición elevada, sino también para contemplar en la distancia la figura imponente del monte más famoso de Japón, que si bien había sido cantado desde los tiempos del Manyōshū, se convierte en el período Edo en un motivo artístico recurrente — por ser también, obviamente, una escenografía propia 
de la región de Kantō y orgullo de los habitantes de Edo. La pareja de biombos que nos ocupaba anteriormente representa también esa escena. El espectador, sentado sobre el tatami entre uno y otro biombo, se sentiría de ese modo rodeado por el paisaje, como si ocupara el mismísimo centro de la llanura. El biombo de la derecha, como hemos visto, está dedicado al motivo de la luna sumergida entre las hierbas (imagen 4), mientras que el biombo de la izquierda muestra el monte Fuji asomando sobre el herbazal. Seguimos, aun así, en el plano conceptual. A pesar de que en Edo sí aparece descrita la llanura en guías de viaje, el interés de los artistas no reside en la representación realista del paisaje. El mejor ejemplo de ello es la serie de grabados ukiyoe que Katsuhika Hokusai (1760-1849) dedica al monte Fuji: Treinta y seis vistas del monte Fuji (Fugaku sanjūrokkei, 1831-33). Se trata de un conjunto de xilografías que muestran la silueta de la montaña desde gran variedad de puntos de vista, muchas veces desde rincones insospechados o con perspectivas imposibles. Muchos de los lugares son reales, pero su composición es en su mayor parte imaginaria, con elementos añadidos o distorsionados y con personajes cuya presencia, aun sirviendo para mostrar alguna que otra escena cotidiana, no deja de estar supeditada al conjunto del paisaje. Una cualidad que no impidió que el libro de ilustraciones se convirtiera en un éxito de ventas, hasta el punto de que en una segunda edición Hokusai decidiría añadir diez grabados más. En realidad, los habitantes de Edo no estaban tan interesados en la fidelidad de la obra — que en cierto modo funcionaba igual que cualquier otra guía de lugares célebres-, como en la originalidad de su expresión, fuente de asombro y entretenimiento: a través de las ilustraciones se acercaban a los paisajes naturales de su propia ensoñación, al tiempo que pasaban el rato gozando de una estética que ya no era de corte aristocrático, sino popular, puesto que poco importaba si entendían o no la referencia o la alusión.

Para encontrar una representación naturalista de la llanura de Musashino en la pintura necesitaremos esperar hasta principios del siglo Xx. Más aún para hallar una panorámica del noble Fuji en la que este aparezca junto a humildes campos de cultivo. Concretamente hasta 1928, en un grabado ukiyoe intitulado "Musashino" (imagen 6) del paisajista Yoshida Hiroshi (1876-1950). En la imagen vemos los campos en la mitad inferior extendiéndose hasta las montañas - difuminadas en la lejanía y en una disposición similar a la de las nubes del biombo que comentábamos previamente- y el Fuji asomándose 
sobre el horizonte. Ahora bien, cabe señalar que este acercamiento al paisaje realista, si bien por un lado se desprende de la idealización clásica, conforma a su vez una idealización distinta del paisaje ligada a la construcción de una nueva identidad japonesa que enfatiza el origen campesino de la nación y la importancia de los campos de cultivo; un proceso de reconstrucción identitaria iniciado en la era Meiji y que se corresponde con la visión "exótica" de los occidentales que visitan el país. En 1868, el geógrafo Ferdinand von Richthofen quedará fascinado por las terrazas de cultivo en las islas de Setonaikai, el mar interior de Japón, y expresará su deseo para que se conserven frente a la amenaza de la civilización (Kogita 2012: 37). En 1878, la exploradora y escritora británica Isabella Bird, tras visitar en 1878 la llanura de Yonezawa, en la prefectura de Yamagata, tilda a esta región de "perfecto jardín del Edén" y "Arcadia asiática”, «rica en el cultivo de arroz, algodón, maíz, tabaco, cáñamo, índigo, alubias, nueces, melones, pepinos, caquis, albaricoques, granadas» (Bird, 2005: 133). De este modo, la "estampa" de Yoshida Hiroshi continúa esta idealización del Japón profundo destacando el fenómeno del cultivo de la tierra (nótese curiosamente la ausencia de nubes en el cielo), mediante una descripción naturalista de Musashino con sus campos de arroz, lo que a su vez representa las transformaciones socio-políticas del período (Flores Urushima, 2015: 4). Así pues, en términos generales, Yoshida Hiroshi no escapa en su obra de cierto proceso de idealización de Oriente, como demuestran especialmente sus grabados dedicados a países como Egipto y la India, los cuales visitó. Sus obras están teñidas de exotismo y son muy representativas de la mirada "orientalista" de la época, de la que Japón, aun siendo parte de "Oriente", participa. Este hecho, que difumina la oposición binaria entre Oriente y Occidente, podría servir de punto de partida para una aproximación crítica a la teoría orientalista de Edward Said, quien pone énfasis en el orientalismo como perspectiva occidental, cuando se trataría más bien de una mirada nacida del contraste entre desarrollo urbano y subdesarrollo urbano, esto es, de la delimitación entre los conceptos de naturaleza y de ciudad. Sea como fuere, la cuestión es que para llegar a la obra de Yoshida, en la que la llanura está presente como modelo "real" y no como mera alusión de la tradición poética, tuvo que suceder antes un cambio de perspectiva en la apreciación de la naturaleza; un cambio que podemos remontar hasta la crónica literaria Musashino (1901) de Kunikida Doppo (1871-1908), cuya 
descripción de la planicie pareciera haber inspirado en algunos de sus pasajes la estampa de Yoshida.

[...] cual océano en marejada, presenta una orografía bastante accidentada. Hasta cierto punto, su aspecto es el de una llanura, aunque sería más apropiado definirlo como un valle, poco profundo, con varios desniveles. Al fondo, casi todo son arrozales y, principalmente, en terreno elevado, se encuentran las huertas que, junto a la arboleda, forman parte de la parcelación del terreno. Es decir, las huertas son la llanura. (Kunikida 2015)

Imagen 6: Yoshida Hiroshi (1928). Musashino [Grabado]. Ver online en Museum of Fine Arts Boston: https://collections.mfa.org/objects/251412/fujiyama-from-musashino-musashino-from-the-series-ten-vie

\subsection{Imagen de Musashino en la era Meiji}

Al inicio de su crónica Kunikida explica que se acerca a Musashino con la intención de descubrir la imagen de la llanura fijada por la tradición literaria, pero se encuentra, en cambio, un paisaje transformado en arboleda; algo que no le impide llegar a la conclusión de que Musashino sigue conservando su hermosura: «¿Qué queda hoy realmente de tan mítico paraje? [...] En primer lugar, la respuesta que debo dar a la pregunta, en pocas palabras, es que la belleza de Musashino sigue igual que antaño» (Kunikida 2015). Más adelante, en el tercer capítulo de un total de nueve, leemos:

Como cuenta la tradición, el antiguo Musashino era bien conocido por su inigualable belleza y su infinita llanura de susuki, sin embargo, en la actualidad, destaca una arboleda. Ciertamente, podríamos decir que es la nueva estampa de este mítico paraje. [...] un espacio natural único donde abunda un nara [roble japonés de hoja caduca] que en invierno pierde todo su follaje, pero del que brota en primavera un verdor chorreante [...]

[...] según parece, los primeros japoneses nunca supieron de la belleza de ese árbol. Más aún, cuando las artes literarias japonesas mencionan el término «arboleda», generalmente nunca se refieren a robles, sino a pinares. (Kunikida 2015) 
De este fragmento podemos deducir lo siguiente: 1. El paisaje de Musashino ha sido transformado en una arboleda; 2. Esta arboleda es considerada por Kunikida un "espacio natural", a pesar de formar parte de una naturaleza alterada por el hombre (quizás sea esa la única manera de entender la naturaleza en la modernidad); 3. Los antiguos japoneses no apreciaban la belleza del roble, prefiriendo más bien el pino de hoja perenne, árbol que desde la tradición china es símbolo de inmortalidad.

De este último punto se intuye, además, que Kunikida considera el bosque de hojas caducas un paradigma de la belleza natural, a diferencia de "los primeros japoneses". Debemos entonces preguntarnos de dónde surge este cambio en la percepción estética de la naturaleza. La respuesta la encontramos en el mismo texto algunas líneas después: «aunque han pasado ya diez años desde que vine a Tokio siendo aún estudiante, no hace mucho que comencé a apreciar la riqueza en matices de la arboleda caducifolia, cosa que descubrí igualmente gracias al siguiente relato» (Kunikida 2015).

El relato en cuestión, del que Kunikida cita un fragmento, es La cita del escritor ruso Iván Turguéniev (1818-1883). En él se describe de forma poética un paseo por una arboleda de abedules. Lo que hace aquí Kunikida es trasplantar esa percepción del bosque ruso a la arboleda de Musashino, lugar que considerará ideal para el paseo (nótese que Kunikida narra sus paseos en la zona de Shibuya, hoy en día en pleno centro de Tokio, en donde se encuentra el paso de peatones más poblado del mundo, por lo que podemos decir que en apenas cien años Shibuya ha pasado de ser un lugar de paseo a un lugar de paso). Pero con ese cambio de percepción, Kunikida no solo está revalorizando la arboleda como belleza natural, sino que además está introduciendo la sensibilidad occidental a la hora de observar el paisaje. De hecho, tal y como escribe el filósofo Karatani Kōjin, Musashino es la primera obra literaria japonesa en la que se trata el tema del paisaje, lo que supone un cambio de perspectiva no solo en la manera de percibir la naturaleza, sino también un punto de inflexión en la historia literaria. En opinión de Karatani, con Musashino y obras de otros autores de la época como Futabatei Shimei (1864-1909), escritor y traductor del fragmento de Turguéniev citado por Kunikida, nace la literatura moderna en Japón; una literatura nueva cuyo primer síntoma es lo que Karatani denomina el "descubrimiento del paisaje". 
Este descubrimiento viene dado por una manera de aproximarse a la naturaleza heredera del romanticismo y del naturalismo europeo, que en cierto modo puede remontarse a Rousseau y su paseos por los Alpes. En Japón, la representación de la naturaleza en el arte antes de la aparición de la literatura moderna o europea consistía en la descripción de los lugares comunes establecidos por la poesía waka: motivos como ciruelos, cerezos en flor, pinos, flores y pájaros. La naturaleza no era el objeto de una observación objetiva. No interesaba la descripción detallada, sino más bien la sugestión, la idea o el concepto (igual que en la pintura clásica china), por lo que el poeta y el artista únicamente trataban de confirmar su posición en la tradición.

Pintar una pineda significaba para el pintor representar el concepto de "pineda", no una pineda existente. Esta visión trascendental del espacio debía dar un vuelco antes de que los pintores pudieran considerar una pineda existente como sujeto pictórico. Es entonces cuando aparece la perspectiva moderna. O para ser más precisos, lo que llamamos perspectiva moderna habría surgido ya en algún momento anterior a ese en forma de una inversión de perspectiva. (Karatani 1993: 27)

Con "inversión de perspectiva" se refiere Karatani a un cambio en la manera en la que el yo percibe no solo el entorno, sino también su propia condición de "yo". El yo moderno actúa como un centro epistemológico que relata sus descubrimientos e impresiones; así, el paisaje no es ya un concepto ligado a una larga tradición literaria, sino algo a ser descubierto por cada individuo mediante su inmersión en él (Thunman 2002). Según Karatani, este "descubrimiento de la naturaleza" deriva en una segunda característica de la literatura moderna: el "descubrimiento de la interioridad", un concepto que irá muy ligado a la aparición de la "literatura del yo" (watakushi shōsetsu), uno de los géneros preferidos entre los autores japoneses de la modernidad. En este sentido, no es extraño que el paseo por la naturaleza vaya íntimamente ligado a la reflexión del yo y al descubrimiento de la propia condición humana:

Tan sólo caminar por caminar, tanto por la izquierda como por la derecha, por todos lados hay cosas para el deleite. Creo sinceramente que esta es la verdadera impronta de Musashino. ¿Dónde podríamos encontrar otro lugar semejante en Japón? Obviamente, ni en Hokkaidō ni en Nasuno. Así pues, ¿dónde? ¿En qué otro lugar existe una relación tan estrecha entre naturaleza y ser humano 
donde se confundan campo y arboleda? Realmente, esta es la razón por la que Musashino cuenta con caminos tan singulares. (Kunikida 2015)

Al priorizar Musashino sobre Hokkaidō, Kunikida revaloriza la naturaleza dominada por la mano del hombre por la que uno se pasea igual que se hace en un jardín inglés, con disposición al asombro, pero sin perdida: «En el actual Musashino nadie se pierde. Lo importante es decidir una dirección, y el secreto está en caminar sin rumbo por otros senderos» (Kunikida 2015). Una naturaleza, además, integrada en las costumbres humanas; el campo en estrecha relación con el ser humano. De este modo, por extensión, el "descubrimiento de la naturaleza" implica a su vez el descubrimiento de las pequeñas historias de los personajes que pueblan el paisaje; una visión naturalista propia de la elite intelectual de la era moderna que podemos percibir en otros autores como Tokutomi Roka (1868-1927) o Tayama Katai (1871-1930). Por ejemplo, la obra de Tokutomi Roka, Naturaleza y vida (1900) plantea el regreso a la naturaleza como una experiencia libertaria con ideas inspiradas en el cristianismo y en Tolstoy, con quien se carteaba y a quien llegó a visitar en Yásnaia Poliana, la finca del autor ruso en mitad del bosque de Tula, en Rusia. La obra de Roka es además una obra de referencia para los movimientos de retorno a lo rural en la era contemporánea. Recientemente, al entrar en Kioto en un café de aspecto rústico de nombre Sōsōtoshite y en cuyo menú había galletitas caseras y quiche, descubrí en la pared, como única decoración, una edición de Naturaleza y vida que estaba enmarcada como si fuera un cuadro, junto a un jarrón con flores. Esta anécdota aparentemente insustancial es muy significativa de los movimientos que promueven el retorno a lo rural y a la "vida sana" en pleno centro urbano. Por su parte, Tayama Katai escribe: «Más que por montañas y ríos y paisajes imponentes, he empezado a sentir interés por las peculiaridades de cada tierra: de su atmósfera y de la sensibilidad de sus gentes» (1981: 238). Estos autores cosmopolitas sentirán un apego especial por Musashino, con sus arrozales y huertos, como si se tratara de su propia tierra natal, y reivindicarán en sus escritos un paisaje cotidiano y sencillo cuya mediocridad es sublimada en algo bello. Lo mismo ocurre con los pintores de la época que introducen el paisajismo europeo influidos por Corot y los impresionistas. Es el caso, por ejemplo, de Kishida Ryūsei (1891-1929). 
Su óleo "Primavera temprana" (Sōshun, 1916) muestra un vulgar camino de tierra franqueado por árboles caducos que se pierde colina arriba entre una arboleda de hojas perennes (imagen 7).

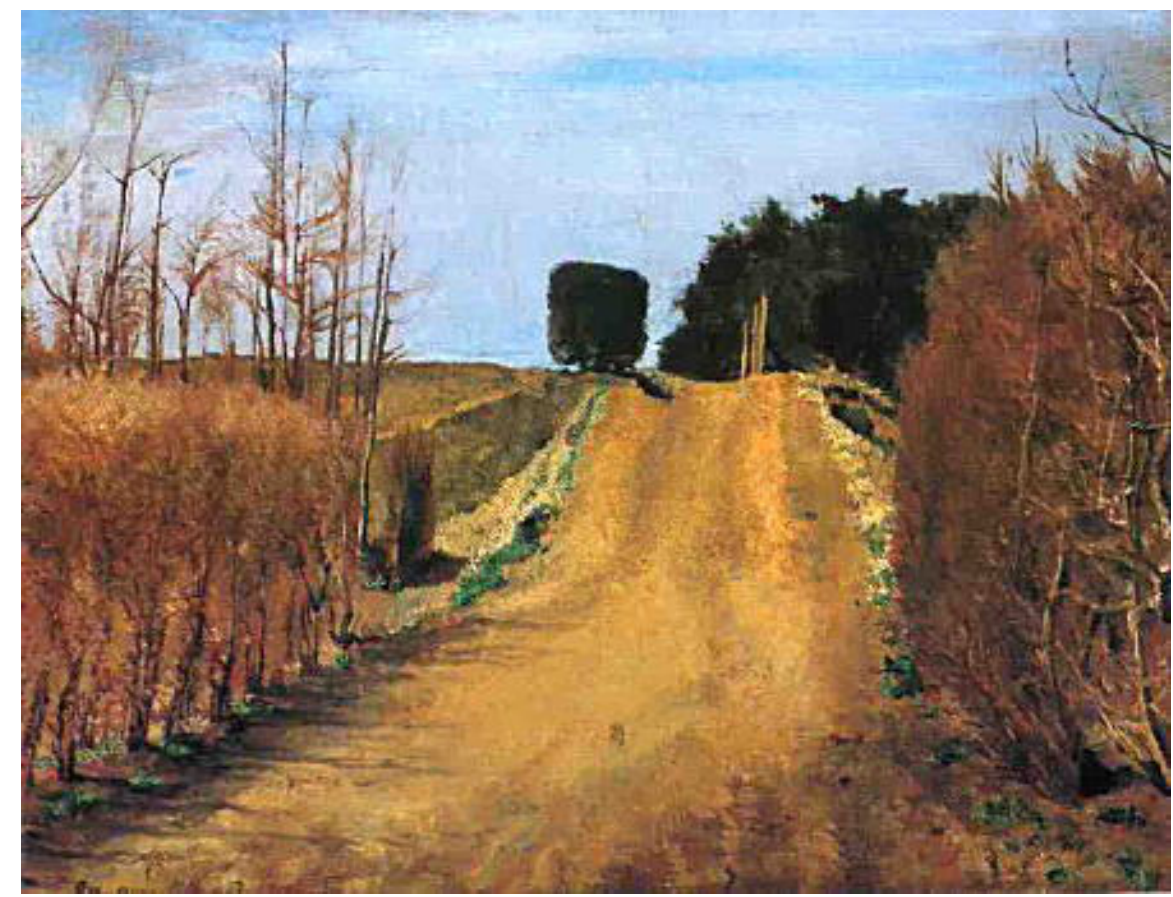

Imagen 7: Kishida Ryūsei (1916), "Primavera temprana" [Pintura]. Fuente: Kishida (1984), Kishida Ryūsei gashū (Colección de pinturas de Kishida Ryūsei), ilustración n. 98.

Es un paisaje realista, sobrio y frío, casi anodino y decadente, en la tónica del gusto literario de la época, desprovisto de todos los tópicos clásicos: planicie, hierbas silvestres, luna, Fuji, etc. Sin embargo, en la misma época, sigue habiendo pintores que se decantan por la imagen tradicional; estos rechazan el uso de óleo para continuar la técnica pictórica japonesa (nihonga) e imponen una visión tradicionalista de la llanura que viene teñida de nostalgia por el Japón perdido tras la apertura a Occidente. Véase, por ejemplo, "Musashino" (1895) de Yokoyama Taikan (1868-1958), en el que reaparece el elemento clásico del monte Fuji visible en el horizonte junto a las típicas hierbas y flores otoñales (obana) en primer plano (imagen 8). La novedad de este paisaje idealizado reside en la incorporación de rocas (elementos omnipresentes en la pintura china) y un solitario árbol que a juzgar por la forma 
de los pétalos y teniendo en cuenta que las plantas alrededor son propias de la estación otoñal, debe de tratarse de un arce (kaede), si bien el color se acerca más al del durazno. Con todo, aunque se trate de un paisaje imaginado, descubrimos otros elementos distintivos de la planicie de Musashino como la presencia de agua en abundancia y un bosque sobre la loma en la parte superior izquierda, quizás en un intento por congeniar la imagen tradicional con la imagen "real" contemporánea del autor. A pesar de todo, no se percibe la huella del hombre y no aparecen campos de cultivo, por lo que se trata de un paisaje intacto, salvaje, cercano a lo mitológico.

\section{Imagen 8: Yokoyama Taikan (1895). Musashino [Pintura]. Nara, Museo Nacio- nal de Nara. Ver online: https://www.narahaku.go.jp/collection/1436-0.html}

En comparación con el cuadro de Yokoyama Taikan, puede parecer que los escritores y pintores naturalistas presentan una mirada mucho más objetiva. No obstante, no hay que perder de vista que ellos también proyectan su Arcadia ideal en un tiempo en el que la llanura está siendo ya colonizada por la ciudad: «Tokio atraviesa Musashino con sus líneas férreas y se extiende conectando directamente con otras áreas» (Kunikida 2015). La primera estación en la zona data del año 1883 y en el año 1907 se conecta Shibuya con Tamagawa, dando pie a la urbanización de los alrededores, por lo que paisajes como el de Kishida Ryūsei debían de ser también una excepción.

En Musashino abundaban también las villas construidas por la elite de Tokio como lugar de retiro: ya fuera para cambiar de aires, por motivos de salud o como refugio de lectura para diletantes. Por ejemplo, la biblioteca en la villa de Iwasaki Koyata (1879-1945), hombre que convirtió Mitsubishi en un gran conglomerado de empresas (zaibatsu), constaba de unos veinte mil ejemplares. Ubicadas sobre lo alto de las colinas — con vistas a la llanura - o en los extremos de la meseta, aprovechaban la pendiente para el cultivo de jardines. Hasta mediados de Meiji solían construirse al estilo de las antiguas shimoyashiki, las villas de los daimyō de Edo, con jardín y casa de té. Pero a partir del año 1883, tras la construcción de Rokumeikan, el primer edificio de estilo occidental en Tokio, se empieza a imitar la arquitectura moderna, con grandes salones que son capricho de millonarios, ejecutivos y hombres de las 
finanzas. El magnate Shibusawa Eiichi (1840-1931), por ejemplo, construye su mansión en Asukayama, lugar famoso por sus cerezos, para impresionar a sus invitados, entre los que contaron personalidades extranjeras como el presidente Grant o Tagore (Soshiroda 1992).

Vemos, así pues, que en la era Meiji sigue existiendo una brecha considerable entre el paisaje imaginado y el paisaje real, cuyo aspecto está cada vez más condicionado por la urbanización de los suburbios. De ahí que no sea de extrañar que autores como Kunikida reaccionen con nostalgia, atraídos por un espacio natural en vías de desaparecer. Como él, y en gran medida debido a su influencia, muchos diletantes desviarán su mirada hacia esos rincones de la llanura que todavía resisten frente al progreso acelerado de Tokio. El mejor ejemplo de ello es la fundación en 1917 de la Asociación de amigos de Musashino, en torno al arqueólogo y folclorista Torii Ryūzō (1870-1953). El mismo año, el parque Inokashira se convierte en el primer parque protegido en las afueras de Tokio. Le seguirá el parque Tama Reien seis años más tarde. En julio de 1918, la Asociación publicará el primer número de la revista "Musashino", donde escritores, folcloristas y aficionados colaborarán para darle voz a la llanura.

Pero la batalla estaba ya perdida. Tras el gran terremoto de Kantō en 1923 (año en el que irónicamente el parque Tama Reien es transformado en un cementerio), la reconstrucción de Tokio acelerará la urbanización de las zonas periféricas, relegando así la imagen de Musashino como espacio natural al terreno de la ficción.

\section{A modo de conclusión}

A lo largo de los siglos la llanura de Musashino ha sido un espacio natural en el que se han proyectado las fantasías de las élites literarias y artísticas de la urbe, primero desde las antiguas y distantes capitales Heijō-kyō (actual Nara) y Heian-kyō (actual Kioto) y más tarde desde Kamakura y desde la propia Edo (actual Tokio). Durante el período Heian destacaron las imágenes de "llanura de hierbas silvestres" (yasō no no) y "llanura de violetas" (murasaki no no), a las que se superpuso en el período Kamakura la de "llanura vasta e 
interminable" (bōbaku no no). Tales descripciones, imaginadas muchas veces desde la lejanía de la urbe, contribuirán a crear una imagen estereotipada de Musashino como lugar salvaje, con frecuencia opuesto a la naturaleza "de bonsái" propia de los jardines de la corte. La llanura se transforma así en un lugar común del arte y la literatura que sobrevivirá hasta la era moderna, a pesar de sufrir cambios drásticos en su paisaje durante el período Edo. Se crea de este modo una gran brecha entre la naturaleza real y la naturaleza imaginada: aun siendo una época en la que el paisaje de la llanura fue alterado profundamente por la mano del hombre a través del arado, el cultivo de arroz y la plantación de árboles para distintos usos, se trata también de la época que produce mayor número de imágenes estereotipadas de Musashino, con elementos característicos de la tradición literaria como las hierbas de otoño, la luna o el monte Fuji. Las razones de esta profusión van desde la aparición de nuevas formas de ocio como el turismo rural a la mera nostalgia de paisajes naturales, cada vez menos frecuentes en la capital. La imagen nostálgica de la naturaleza perdida calará profundamente en la imaginación de los japoneses hasta bien entrado el siglo Xx, si bien ya en los inicios de la modernización de Japón, durante la era Meiji, descubrimos un cambio de sensibilidad en la apreciación del paisaje en escritores como Kunikida Doppo, quienes tratan de descubrir el entorno real de la llanura influidos por las corrientes naturalistas de corte europeo. Musashino, en esta época, pasa así de ser una llanura silvestre a ser una zona donde abundan, por un lado, los campos de arroz (imagen que contribuye a la constitución de una nueva identidad nacional) y, por otro, las arboledas donde los urbanitas aprenden a gozar del paseo, pasatiempo moderno propio de la burguesía. Esta nueva mirada de la naturaleza conllevará cambios en la percepción del yo y del otro (a grandes rasgos el escritor y el campesino), así como cambios en los discursos sobre la naturaleza y su incorporación en el entorno urbano a través de espacios protegidos. Con todo, en un contexto en el que la gran urbe de Tokio le gana terreno a la llanura a pasos agigantados, este cambio de sensibilidad forma parte también de un proceso de idealización de la naturaleza por medio del cual el ciudadano reconstruye su propia identidad de urbanita en contraste con el mundo rural. Y si bien por parte de las élites intelectuales existe un intento por frenar la urbanización desenfrenada, su impulso no resulta suficiente para evitar lo inevitable: la pérdida de la naturaleza frente a la expansión de Tokio, 
una ciudad que relega la llanura de Musashino al espacio de la nostalgia y de la imaginación.

\section{Bibliografía}

BIRD, I. L. (2005) [1878]. Unbeaten Tracks in Japan, New York, Dover Publications.

Flores Urushima, A. (2015). «Territorial prospective visions for japan's high growth: The role of local urban development», Nature and Culture, 10 (1), 12-35

KISHIDA, R. (1984). Kishida Ryūsei gashū岸田劉生画集 (Colección de pinturas de Kishida Ryūsei), Tokio, Iwanami shoten.

Kunikida, D. (2016). Musashino y otros relatos (J. Camacho Cruz, Trans.), Valencia, Chidori Books [versión digital].

KunIKIDA, D. (2006) [1901]. Musashino 武蔵野, Tokio, Iwanami shoten.

IKETANI, T. (2005). « Musashino et les débats autour de la recherche sur les terroirs », Ebisu, 34, pp. 125-146.

KogITA, T. (2012). "“Musashino" no chishigaku: bunka keikan kara shinshō fükei e»『武蔵野』の地誌学：文化景観から心象風景へ (The Topography of "Musashino": From Cultural Landscape to Imagined Landscape), Jinbun-shizen-ningen kagakukenkyü 28 人文・自然・ 人間科学研究 No. 28, pp. 31-52.

KaRatani, K. (1993). Origins of modern Japanese literature, Durkham, Duke University Press.

KYōKA, I. (2016). Laberinto de hierba, Maestros de la literatura japonesa 21, Gijón, Ediciones Satori.

Miramoto, T. (1981). Musashino no kaihatsu to keikan no hensen 武蔵野 の開発と景観の変遷 (Desarrollo y cambios en el paisaje de $\mathrm{Mu}$ sashino), Tokio, Miraisha.

Окимото, D. (2009). «Musashino to nihon no fukeiga»武蔵野と日本の風 景画 (Musashino y la pintura paisajística japonesa), Asteion, 70 ア ステイオン (70), pp. 210-213.

SAIto, C. (1834). Edo meisho zue 江戸名所図会 (Guía ilustrada de lugares célebres de Edo), Tokio, Nihon meisho füzoku zue 4, Edo no maki II 日本名所風俗図会 4 江戸の巻II.

SAITo, G. (1838). Tōtosaijiki 東都歳事記 (Guía ilustrada de lugares célebres de Edo), Tokio, Nihon meisho füzoku zue 3, Edo no maki I 日本名 
所風俗図会 4 江戸の巻I.

SAITo, K. (1815). Musashino-banashi武蔵野話 (Historias de Musashino), Tokio, Nihon meisho füzoku zue 3, Edo no maki I 日本名所風俗 図会 3 江戸の巻I.

SAKURAI, S. (2010). «Musashino no hatasaku bunka: Saitama ken Santome chiiki wo rei toshite»武蔵野の畑作文化：埼玉県三富地域 (La cultura de labranza de Musashino: el caso de la región de Santome), Kokusai bunka kenkyū ronshū, vol. 8 国際文化研究論集 第8巻, pp. 32-47.

SiEBERT, L. (2006). «Japan's Edo-Tokyo Region Mapped and Interpreted with GIS», Reading Historical Spatial Information from around the World Studies of Culture and Civilization Based on Geographic Information Systems Data, vol. 24, pp. 155-164.

Soshiroda, A. (1992). «Senzen no Musashino ni okeru bessō no ricchi to sono seiritsu haikei ni kansuru kenkyū» 戦前の武蔵野における別 荘の立地とその成立背景に関する研究（Investigación en torno a la localización y establecimiento de las villas en el Musashino de la preguerra), Zōen zasshi, 55 (5) 造園杂倠誌55 (5), pp. 373-378.

SumidA, K. (2015). «Musashino daichi no kasen to mizu kankyō» 武蔵野 台地の河川と水環境 ( Rivers and Hydrological-Environment of Musashino-Upland in Tokyo), Komazawa chiri, 51 駒澤地理51, pp. 35-58.

Thunman, N. (2002). «Landscape in modern Japanese literature and the impact of translations», Africa \& Asia, No 2, pp. 116-124.

TaYama, K. (1981) [1917]. Tōkyō no sanjunen 東京の三十年 (Treinta años en Tokyo), Tokio, Iwanami shoten.

TокUтомі, R. (1958) [1900]. Shizen to ningen 自然と人生 (Naturaleza y vida), Tokio, Iwanami bunko.

TorII, S. (1924). Musashino oyobi sono shüi 武蔵野及其周囲（Musashino y su entorno), Tokio, Isobe Kōyōdō.

Tsuyoshi, T., Honda, M., eds. (1941). Musashino 武蔵野，Tokio, Kagakushugi kōgyōsha.

UCHIDA, Y. (2008). «Fūkei toshite no Musashino: Kunikida Doppo Musashino wo yomu» 風景としての武蔵野一国木田独歩『武蔵野』を読 屯 (Musashino como paisaje: lectura de Musashino de Kunikida Doppo), Zōen zasshi, 53 (5) 国士館大学地理学報告 16, pp. 57-63. 
UnNo, H. (1999). «Shin-Musashino ron: fūkeikūkanshi no tame ni» 新・武 蔵野論：風景空間史のために（Nueva teoría de Musashino: para una historia del espacio y el paisaje), Nihon oyobi nihonjin, (1636) 日本及日本人 (1636), 10, pp. 17-26.

WatanukI, I. (1935). Shūraku keitai ron 聚落形態論 (Morfología de los asentamientos humanos), Tokio, Kokon shoin. Yamane, M. ET $\boldsymbol{A L}$. (1990). «Musashino no imeji to sono henka yōin ni tsuite no kōsatu» 武蔵野のイメージとその変化要因についての考察 (Estudio sobre la imagen de Musashino y los factores que comportan cambios en esa imagen), Zōen zasshi, 53 (5) 造園雑誌53 (5), pp. 215-220.

Yanagita, K. (1918). Musashino no mukashi 武蔵野の昔 (El Musashino de antaño), Nihon gendai bungaku zenshū, Tokio, Sōgensha. 
